\title{
Güney ve Doğu Anadolu’ da Soğurulmanın (1/QC) Yanal Heterojenitesi
}

\author{
Ufuk Aydin ${ }^{1 *}$ \\ ${ }^{1}$ Atatürk Üniversitesi, Oltu Yer Bilimleri Fakültesi, Maden Mühendisliği Bölümü (ORCID: 0000-0001-7981-9550)
}

(Illk Geliş Tarihi 9 Ocak 2020 ve Kabul Tarihi 31 Mart 2020)

(DOI: 10.31590/ejosat.672557)

ATIF/REFERENCE: Aydın, U. (2020). Güney ve Doğu Anadolu' da Soğurulmanın (1/QC) Yanal Heterojenitesi. Avrupa Bilim ve Teknoloji Dergisi, (18), 850-857.

\section{$\ddot{O ̈ z}$}

Bu çalışma coda kalite faktörü ile sismik aktivite, tektonik süreksizlik ve litosferik heterejonite arasındaki olası uyum ve uyumsuzluklar belirlenmeye çalışılmıştır. Bu amaç ile farklı tektonik sistemler üzerinde bulunan ve sismik aktivitesi birebirinden farklı olan Kemaliye, Diyarbakır ve Erzurum sismik istasyonlarından elde edilen Sg dalgaları kullanılmıştır. Birbirinden farklı fay zonlarının etkisi altındaki

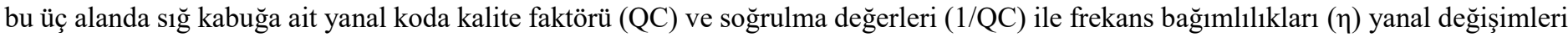
belirlenerek karşılaştırmalı olarak incelenmiştir. Çalışmada Qc ve $\eta$ değerlerini elde etmek için izotropik tek saçılma yöntemi kullanılmıştır. En düşük koda Q1 $=(82 \pm 5)$ değeri Kemaliye istasyonundan, en yüksek Q2 $=(90 \pm 5)$ değeri Diyarbakır istasyonundan ve Q3=(86 \pm 3$)$ değeri de Erzurum istasyonundan elde edilmiştir. En yüksek soğurma değerleri Kemaliye istasyonunda elde edilirken en düşük soğurma değerleri Erzurum istasyonundan elde edilmiştir. En yüksek $\eta$ değerleri $0.96 \mp 0.04$ olarak Kemaliye sismik istasyonu verilerinden en düşük $\square$ değeri $0.85 \pm 0.03$ olarak Diyarbakır istasyonu kayıtlarından elde edilmiştir. Erzurum istasyonu için ise $\square$ değeri $0.88 \mp 0.02$ olarak elde edilmiştir. Koda değerleri 82 ve 90 , frekans bağımlılı̆ı değerleri 0.66 ve 1.27 aralığında elde edilmiştir. Üç bölgenin 1/QC ve frekans bağımlılığı değerleri, kabuğun sismotektonik aktivitesindeki bölgesel farklılıklara bağlı olarak 0.001-0.014 arasında değiş̧mektedir. Kemaliye bölgesine ait yanal soğrulma değerlerinin Erzurum ve Diyarbakır bölgelerinden oldukça farklı bulunmuş olması bu bölgenin tektonik olarak diğer iki bölgeden daha aktif olduğu gerçeği ile desteklenmiştir. Üç istasyona ait Koda ve frekans bağımlılığı değerleri ile bölgede bulunan üç farklı sismik rejim ve litosferik kabuk yapısına ait yeni bilgiler elde edilmiştir.

Anahtar Kelimeler: Koda soğrulması, Kıtasalkabuk, Sismodinamik özellikler, Tektonikyapılar.

\section{The Lateral Heterogeneity of Attenuation $\left(1 / Q_{C}\right)$ in Southeasternan Anatolia}

\begin{abstract}
In this study, possible adaptations and inadaptations between the coda quality factor and seismic activity, tectonic discontinuity and lithospheric heterogeneity were attempted to be determined. For this purpose, Sg waves obtained from Kemaliye, Diyarbakir and Erzurum seismic stations, which are on different tectonic systems and whose seismic activities are different from one another, have been used. In these three areas under the influence of different fault zones, the lateral code quality factor (QC) and attenuation values $(1 / \mathrm{QC})$ and frequency dependence $(\eta)$ lateral chance of the shallow crust have been determined and analyzed comparatively. The single isotropic scattering method has been used to obtain Qc and $\eta$ values in the study. The lowest coda value $Q 1=(82 \pm 5)$ was obtained from Kemaliye station, the highest value Q2 $=(90 \pm 5)$ was obtained from Diyarbakır station and Q3 $=(86 \pm 3)$ value was obtained from Erzurum station. The highest attenuation values were obtained at Kemaliye station, while the lowest attenuation values were obtained at Erzurum station. The highest $\eta$ values were obtained from Kemaliye seismic station data as $0.96 \mp 0.04$ and the lowest $\eta$ value was obtained from Diyarbakır station records as $0.85 \pm 0.03$. The value for Erzurum station $\eta$ was obtained as $0.88 \mp 0.02$. Coda values were obtained in the range of 82 and 90 and frequency dependence values 0.66 and 1.27. The 1/QC and frequency dependence values of the three regions range from 0.001 to 0.014 , showing regional differences in the seismotectonic activity of the crust. The fact that the lateral attenuation
\end{abstract}

\footnotetext{
* Sorumlu Yazar: Atatürk Üniversitesi, Oltu Yer Bilimleri Fakültesi, Maden Mühendisliği Bölümü Erzurum, Türkiye, (ORCID: 0000-0001-79819550)
} 
values of Kemaliye region were found to be quite different from the regions of Erzurum and Diyarbakir was supported by the fact that this region was tectonically more active than the other two regions. New information has been obtained for coda and frequency dependence values of the three stations and three different seismic regimes and lithospheric crustal structure in the region.

Keywords: Coda attenuation, Continental crust, Seismodynamics properties, Tectonics structures.

\section{Giriş}

Dünya mükemmel esnek değildir ve sismik enerjinin bir kısmını sürtünmeli kayma yoluyla 1sıya dönüştürürken sismik dalga boylarına kıyasla çok küçük boyutlardaki yayıcı ortamda anormal yapısal kusurları içerir (Sato, Fehler, \& Maeda, 2012). Bir bölgede deprem riskini belirleyen parametrelere ilaveten sismik kaynak zonlarının büyüklüğü ile faylanma yoğunluğu veya ortamın tektonik inhomojenitesi de değerlendirilebilir. Sismik dalgalar içinden geçtikleri ortamın birçok farklı fiziksel ve kimyasal özellikleri etkisi altında soğurulurlar ve ayrıca özellikle tektonik süreksizliklerine bağlı olarak saçılırlar. Bu yüzden sismik dalgaların soğrulma veya saçılma özellikleri içinden geçtikleri ortamın tektonik heterojenitenin bir göstergesi olarak değerli bilgiler sunarlar. Anadolu plakası gibi sismik yönden oldukça aktif ve karmaşık tektonik birimlere sahip bölge için soğrulma özelliklerinin araştırılması kabuk içi tektonik farklılıkların ve deprem zonlarının belirlenmesi için oldukça önemlidir. Kalite Faktörü Q, sismik dalganın her bir dönümde kaybettiği enerjinin toplam enerjiye oranı olarak tanımlanan boyutsuz bir birimdir (Johnston \& Toksöz, 1981; Knopoff, 1964). Ayrıca kalite faktörü Q nun tersi olan Q-1 soğrulma olarak tanımlanmaktadır.

Doğrudan gelen S dalgalarından sonra oluşan koda (tail) dalgası gurubu kabuk ve manto içinin ortamın homojen olmaması ile ilgilidir (Aki, 1969; Aki \& Chouet, 1975). Bölgesel Koda kalite faktöründeki değişimler bölgesel tektonik, sismik risk analizi ve mühendislik sismolojisini daha iyi anlayabilmemiz için kullanılmaktadır (Jin \& Aki, 1988; Singh \& Herrmann, 1983). Sismograflardan kaydedilen yerel depremler üst manto ve üst kabuğa ait sayısız heterojenitenin sıradan dağılımı tarafından geri saçılmış dalgacıkların oluşturduğu bir üst düşüm olarak kabul edilir (Aki, 1969; Rautian \& Khalturin, 1978). Aki sismik koda dalgalarını saçılma ile oluştuğu için zaman ortamında koda soğrulma farklılıklarının yüzey stresini izlemekte kullanılabileceğini belirtmiştir (Aki \& Chouet, 1975; Jin \& Aki, 1988) . Koda dalgaları rastgele bir saçılma işlemi sonucunda oluştuklarından kaynak etkileri yerine, ortamın etkilerini yansıtırlar (Aki, 1969; Aki \& Chouet, 1975). Dünya çapında, ortamın sismik aktivite karakteristiğini ve sismik olarak durgun bölgelerin sismik olarak aktif bölgelerden ayırt etmek için sayısız sismik dalga soğrulması çalışmaları yapılmıştır (Aki, 1969; Aydın, 2015; Giampiccolo, Gresta, \& Rascona, 2004).

\section{DoğuveGüneydoğuAnadolu'nunTektoniği}

Arabistan levhası, Bitlis-Zagros Bindirmesi (BZB) veya Güneydoğu Anadolu Bindirmesi boyunca Avrasya plakasının altına dalarak çarpışmışlardır (Sengor, 1980).Bitlis Zagros Bindirmesi Kıta-Kıta çarpışmasının en önemli jeolojik yapılarından biri olup iran sınırına kadar ulaşmaktadır (Sengör, 1979) (Şekil 1.). Arap levhasının kuzeye doğru itilmesi Doğu Anadolunun batıya doğru kaçma tektoniği oluşmasına sebep olmaktadır (Sengör, 1979). Bu sıkışma tektoniği sonucunda Kuzey Anadolu Bloğu doğuya ve Anadolu Bloğu ise batıya doğru hareket etmektedir (McClusky, Reilinger, Mahmoud, Ben Sari, \& Tealeb, 2003) (Şekil 1.). Bu hareket ile Anadolu Levhasının kuzey sınırını oluşturan Kuzey Andolu Fay Zonu (KAFZ) sağ-yanal, güney sınırını oluşturan Doğu Anadolu Fay Zonu' da (DAFZ) ise sol-yanal haekete sahip fay zonları olarak Karlıva Üçlü Eklemin' de (KÜE) birleşirler (Allen, 1969; Barka \& KadinskyCade, 1988; Ketin, 1969; McKenzie, 1970; Toksöz, Shakal, \& Michael, 1979) (Şekil 1.). Malatya-Ovacık Fay Zonu (MOFZ), Erzincan yakınlarındaki NAFZ’ dan 240 km uzunluğunda sol yönlü doğrultu atımlı fay zonudur (Bozkurt, 2001). 


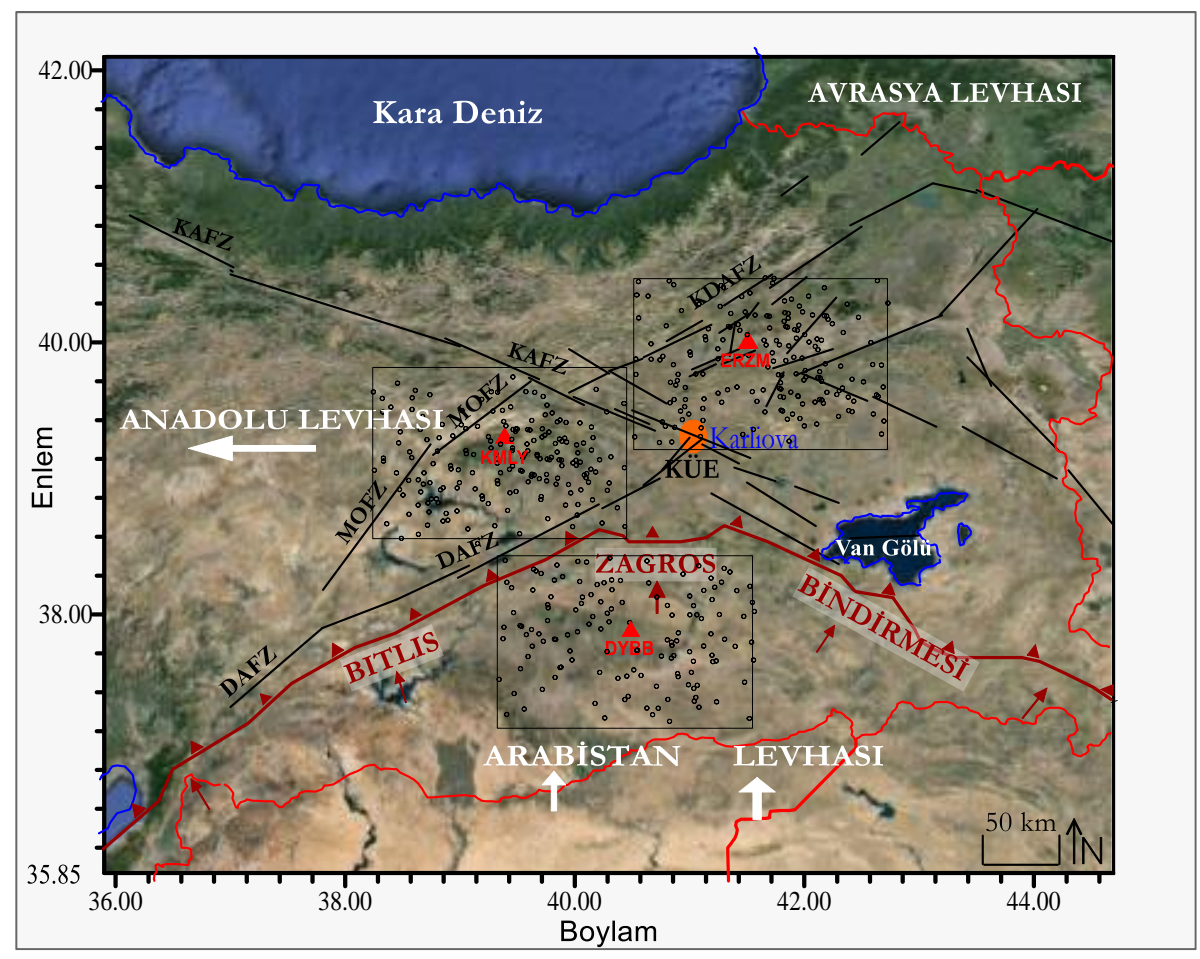

Şekil 1. Çalışma alanına ait büyük ve önemli tektonik yapıları gösteren harita. Levhalar ve hareket yönleri beyazi oklar ile ana fay hatları siyah çizgiler ile gösterilmiştir. Çalışmada kullanılan üç istasyona ait veri sınırları dikdörtgenlerle ve kullanılan depremlerin episantr dă̆llımları siyah çemberler ile gösterilmiştir. Kullanılan sismik istasyonlar kırmızı büyük üçgenler, Bitlis Zagros Bindirmesi kahverengi çizgi ve küçük üçgenler, turuncu daire Karlıova Üçlü Eklemini temsil etmektedir. KAFZ: Kuzey Anadolu Fay Zonu; KDAFZ: Kuzey Doğu Anadolu Fay Zonu; KÜE: Karlıova Üçlü Eklemi; DAFZ: Doğu Anadolu Fay Zonu; MOFZ: Malatya Ovacık Fay zonuı (Barka \& Kadinsky-Cade, 1988; Bozkurt, 2001)

\section{Meteyal veMetot}

Koda dalgası deprem dalgalarının kabukta var olan süreksizlikler ve heterojen ortam nedeniyle dalgaların saçılmaları sonucunda oluşmaktadır. Bu çalışmada (Aki, 1980) tarafından kullanılan ve (Sato, 1977) tarafından geliştirilen tek izotropik saçılma yöntemi kullanılmıştır (Aki \& Chouet, 1975; Sato, 1977). (Sato, 1977) modeli kaynak ve bir alıcı-kesit alanı $\sigma$ olan sonsuz kapasite ve bir N saçılması rastgele bir dağıtım tarafından doldurulan sonsuz ortamda gömülü olduğunu varsayar. Bu modelde koda dalga zaman aralığ genlik modeli karekök ortalama metodu ile aşağıdaki gibi yazılabilir:

$$
\mathrm{E}(\mathrm{r}, \mathrm{w} \mid \mathrm{t})=\mathrm{N} \sigma \Omega /\left(4 \pi \mathrm{r}^{\wedge} 2\right) \mathrm{K}(\alpha)
$$

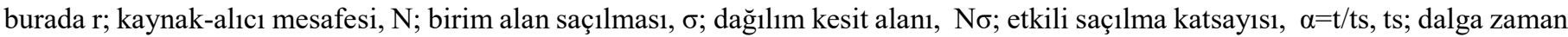
aralığ $1, \Omega(\omega)$; bir birim içinde kaynak tarafından yayılan toplam enerji frekans bandı açısıdır. $K(\alpha)$ geometrik kayma faktörü,

$$
\mathrm{K}(\alpha)=1 / \alpha \ln [(\alpha+1) /(\alpha-1)]
$$

olarak ifade edilir. Cisim dalgaları ve enerji azalımı yayılan geometrik birleştirilerek olarak sismogram süzülmüş bir dar bant ortamı üzerinde koda dalgasının karekök ortalama metodu genlik enerji ile ilişkilidir ve aşağıdaki gibidir:

$$
\mathrm{A}(\mathrm{r}, \mathrm{w} \mid \mathrm{t})=1 / \mathrm{w}|(\Omega(\mathrm{w}) \Delta \mathrm{f}) / 2 \pi \rho \mathrm{L}|^{\wedge}(1 / 2)|\mathrm{K}(\alpha)|^{\wedge}(1 / 2) / \mathrm{r} \quad[\exp \rrbracket \wedge(-\mathrm{wt} / 2 \mathrm{Q})
$$

Burada $L=1 / \mathrm{N} \sigma$; ortalama serbest yol. Kaynak ve yol şartlarını yeniden düzenleyerek ve doğal logaritma alarak, en son aşağıda olduğu gibi elde edilir:

$$
\ln \llbracket \mathrm{A}(\mathrm{r}, \mathrm{e} \mid \mathrm{t})(\mathrm{K}(\alpha)) \rrbracket=\ln \mathrm{C}-(\pi \mathrm{f} / \mathrm{Q}) \mathrm{t}
$$


Son olarak bu çalışmada kullanılan frekans aralığı için azalım-frekans bağımlılı̆̆ aşağıdaki gibi uygulanabilir. Burada f frekans, Q0 $1 \mathrm{hz}$ deki Qc yi, $\eta$ ise QC' nin frekans bağımlılı̆̆ını ifade etmektedir.

$$
\text { Q_C }=\text { Q_ } 0 f^{\wedge} \eta
$$

\section{VeriTabanı}

Bu çalışmada Kuzey Anadolu Fay Zonu ile Doğu Anadolu Fay Zonu arasında bulunan KMLY istasyonu kayıtları, Kuzey Doğu Anadolu Fay Zonlarında bulunan ERZM istasyonu ve Bitlis Zagros Bindirmesinin kuzeyinde kalan DYBB istasyonu kayıtlarından elde edilen toplam 353 deprem verisi kullanılmıştır. Çalışma için seçilen istasyonlara ait üç alan da birbirine eşit olacak şekilde seçilmiş̧ir (Tablo 1, Şekil 1.). Deprem episantr dağılımları ve deprem sayıların, derinlik, magnitüd parametre değerlerinin birbirlerine yakın seçilmesine özen gösterilmiştir. Çalışma için 2006 ile 2015 yılları arasında Atatürk Üniversitesi Deprem Araştırma Merkezi tarafindan işletilen ERZM ve KMLY ile Boğaziçi Üniversitesi Kandilli Rasathanesi ve Deprem Araştırma Merkezi tarafından işletilen DYBB sismik istasyonlarına ait düşey bileşen kayıtlar kullanılmıştır. Veri alınan bu üç sismik istasyon $0.5-100 \mathrm{~Hz}$ frekans bandında, $96 \mathrm{db}$ dinamik aralığı veri alan CMG-TD3 geniş bant sismometreleri ile donatılmıştır. Seçilen 345 depremin odak derinlikler 1-19 km, episantr uzaklıkları 17 ile $189 \mathrm{~km}$ ve magnitüdleri de 3 ile 5.1 aralığında değişmektedir (Şekil 1.)..

Tablo 1. Çalışmada kullanılan deprem istasyonları koordinatları ve deprem saylları.

\begin{tabular}{llllll}
\hline No & İsim & K1saltma & Enlem & Boylam & Deprem sayıs1 \\
\hline 1 & Kemaliye & Q1-KMLY $_{1}$ & $38.53-39.68$ & $38.13-40.42$ & 127 \\
2 & Diyarbakır & Q2-DYBB $_{2}$ & $37.24-38.39$ & $39.22-41.51$ & 108 \\
3 & Erzurum & Q$_{3}$-ERZM & $39.32-40.47$ & $40.55-42.84$ & 118 \\
\hline
\end{tabular}

Kullanılan düşey bileşenlerdeki sinyal gürültü oranı 4 ten daha düşük olan sinyaller kullanılmamıştır. Koda penceresi genişliği 20 saniye olarak seçilmiştir. İlk kayma zamanı S dalgası varış zamanından 4 saniye sonra ve en büyük kayma zamanı (ts +24$)$ saniye alınarak hesaplamalar yapılmıştır. Qc hesaplamalarında A $(\mathrm{t}=\mathrm{ts}+4)$ saniye ve $\mathrm{B}(\mathrm{ts}+24)$ saniye ile sınırlı, merkez frekansı $1.5 \mathrm{~Hz}(1-2)$, $3 \mathrm{~Hz}(2-4), 6 \mathrm{~Hz}(4-8), 12 \mathrm{~Hz}(8-16)$ ve $20 \mathrm{~Hz}$ (16-24) olan Butterworth filtresi ile süzgeçlenmiş veriler kullanılmıştır. Şekil 2'de kullanılan ERZM istasyonu kaydının veri işlemleri örneklemesi gösterilmiştir. Lokal depremlerde S dalga kodası genlikleri yatay ve düşey bileşenlerde çok az fark etmektedir (Sato et al., 2012) . Bu çalışmada düşey bileşen kayıtları kullanılmıştır.

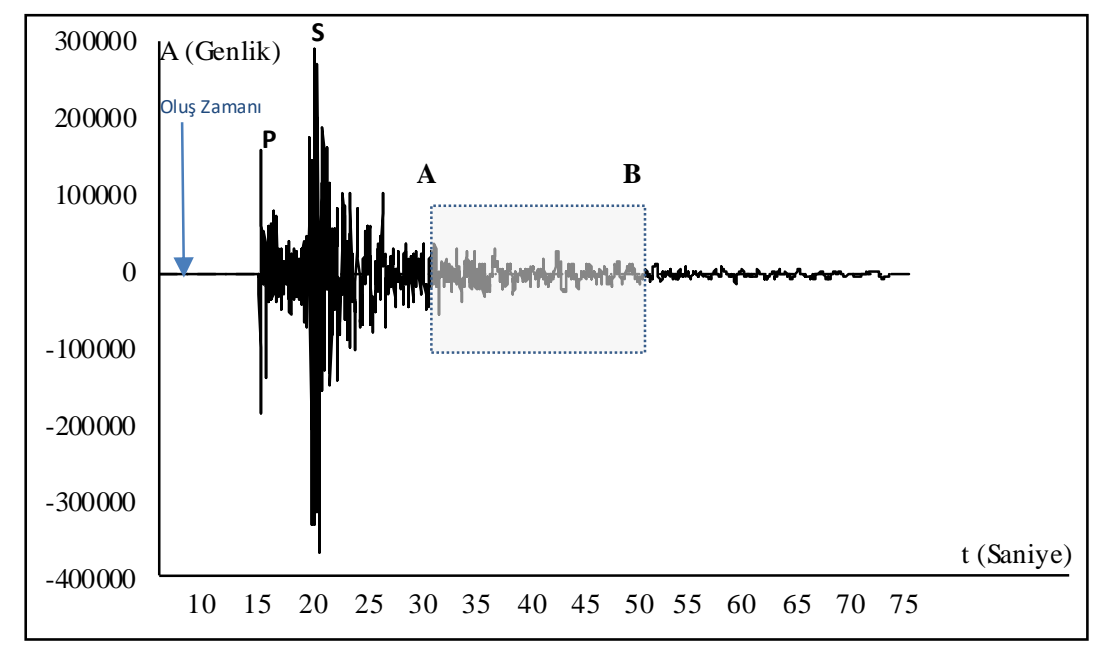

Şekil 2. Veri işlem örneği. Qc hesaplamalarında A oku ile $(t=t s+4 s)$ ve B oku ile $(t=t s+24 s)$ ile pencere sinırlarl, $P$ ile $P$ dalgası varlşl $S$ ile S dalgası varış zamanı gösterilmişsir. Sinyaller merkezi 1.5, 3, 6, 12, $20 \mathrm{~Hz}^{\prime}$ de frekansta filtrelendi.

\section{Bulgular}

Her üç istasyonun için QC ve 1/QC değerleri 1.5, 3, 6, 12, $20 \mathrm{~Hz}$ frekansları ve frekans bağımlılığı ( $)$ değerleri hesaplanmıştır (Şekil 3 ve 4, Tablo 3 ve 4). Üç çalışma alanına ait 1/QC soğurulma değerleri frekansın fonksiyonu olarak Şekil 5' da gösterilmiştir. Bu şekilde düşük frekans değerlerinde QC değerindeki büyük saçılma ve QC değerinin frekansa bağlı olarak artığı görülmektedir. $1 \mathrm{~Hz}$ 
frekansında Kemaliye istasyonundaki depremlerden elde edilen koda değeri Qf= $(82 \mp 5) \mathrm{f} 0.96 \mp 0.04$, Diyarbakır istasyonundan

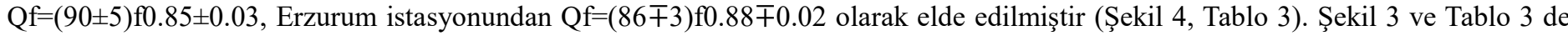
görüldüğü gibi Koda değerleri en yüksek DYBB bölgesinde en düşük ise KMLY bölgesinden elde edilmiştir. Frekans bağımlılığı değerleri 0.66 ile 1.27 arasında değişmektedir. Frekans artıkça QC değerlerinde bir artış görülmektedir. Frekans bağımlılı̆̆ı değerleri en yüksek değerini 0.73 ile 1.27 arasında KMLY istasyonu kayıtlarından elde edilirken, en düşük değeri ise 0.66 ile 1.1 arasında DYBB istasyonundan elde edilmiştir. ERZM bölgesinden 0.7 ile 1.17 arsında diğer iki istasyonun arasında değerler elde edilmiştir. En düşük 1/QC değerleri 0.001 ile 0.0085 arında KMLY istasyonundan elde edilmiştir. En yüksek 1/QC değerleri ise 0.0015 ile 0.014 arasında ERZM bölgesinden elde edilmiştir. DYB ve ERZM ye ait 1/QC değerleri birbirine oldukça yakın olarak bulunmuştur (Tablo 4, Şekil 5 ve 7.). Fonksiyonlardan ve doğrusal grafik denklemlerinden de görüldüğü gibi soğrulma değerleri ERZM ve DYBB istasyonunda hemen hemen birbirine eşit KMLY bölgesinde ise diğer iki istasyona kıyasla daha fazla elde edilmiștir (Şekil 6.). 1/QC(f) değerleri frekans ile ters orantılı olarak azalan bir değer göstermektedir (Şekil 5.). Düşük Qc ve yüksek frekans bağımlılık değerleri Kemaliye'de elde edilmiş ve bu da tüm bölgelerde en yüksek tektonik aktiviteye sahip olduğunu göstermektedir (Şekil 3, 4, 5 ve Tablo 3.). Çalışmadan elde edilen bulgular üç bölgeye ait sismisite ve tektonik yapı ile uyumludur (Şekil 6.).

Tablo 2. $\ddot{U}_{c}$ istasyonun $1.5,3,6,12,20 \mathrm{~Hz}$ frekanslarına ait $Q_{C}$ ve standart sapma değerleri.

\begin{tabular}{llll}
\hline $\mathrm{Hz}$ & $\mathrm{Q}_{1}-\mathrm{KMLY}$ & $\mathrm{Q}_{2}$-DYBB & $\mathrm{Q}_{3}$-ERZM \\
\hline Say1 & 127 & 108 & 118 \\
\hline 1.5 & $136 \pm 9$ & $137 \pm 6$ & $130 \pm 30$ \\
3 & $187 \pm 20$ & $185 \pm 11$ & $170 \pm 18$ \\
6 & $284 \pm 29$ & $278 \pm 27$ & $253 \pm 25$ \\
12 & $486 \pm 124$ & $464 \pm 128$ & $421 \pm 18$ \\
20 & $751 \pm 142$ & $710 \pm 170$ & $646 \pm 29$ \\
\hline
\end{tabular}

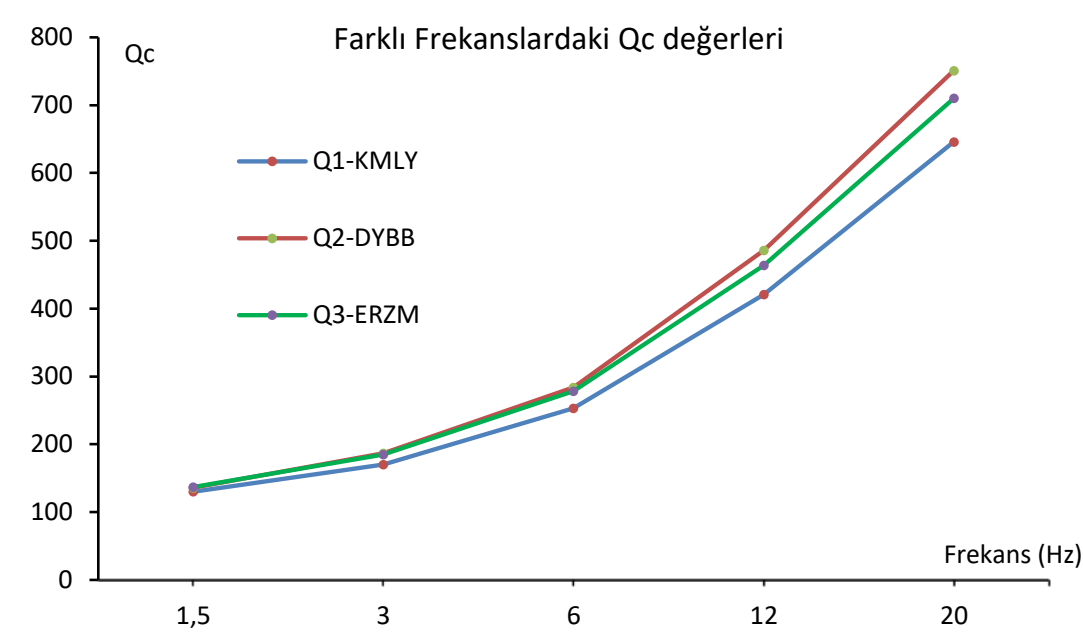

Şekil 3. KMLY, DYBB ve ERZM istasyonlart için $Q_{C}(f)$ grafiği $\left(Q_{1}, Q_{2}, Q_{3}\right)$.

Tablo 3. Kemaliye Diyarbakır ve Erzurum istasyonlarının enlem boylamlarl. $1 \mathrm{~Hz}$ frekansında koda $\left(Q_{0}\right)$, frekans bağımlılı̆̆ $(\eta)$ ve standart sapma değerleri.

\begin{tabular}{lll}
\hline No & K1saltma & $\mathrm{Q}_{\mathrm{C}}=\mathrm{Q}_{0}(\mathrm{f})^{\eta}$ \\
\hline 1 & $\mathrm{Q}_{1}-$ KMLY & $\mathrm{Q}_{1}=(85 \mp 5) \mathrm{f}^{0.96 \mp 0.04}$ \\
2 & $\mathrm{Q}_{2}$-DYBB & $\mathrm{Q}_{2}=(90 \pm 5) \mathrm{f}^{0.85 \pm 0.03}$ \\
3 & $\mathrm{Q}_{3}$-ERZM & $\mathrm{Q}_{3}=(86 \mp 3) \mathrm{f}^{0.88 \mp 0.02}$ \\
\hline
\end{tabular}

Tablo 4. Kemaliye Diyarbakır ve Erzurum istasyonlarında 1.5, 3, 6, 12, $20 \mathrm{~Hz}$ frekansları için $1 / Q_{C}$ değerleri.

\begin{tabular}{llll}
\hline $\mathrm{Hz}$ & $1 / \mathrm{Q}_{1}-\mathrm{KMLY}$ & $1 / \mathrm{Q}_{2}-\mathrm{DYBB}$ & $1 / \mathrm{Q}_{3}-\mathrm{ERZM}$ \\
\hline 1.5 & 0.007353 & 0.007299 & 0.007692 \\
3 & 0.005348 & 0.005405 & 0.005882 \\
6 & 0.003521 & 0.003597 & 0.003953 \\
12 & 0.002058 & 0.002155 & 0.002375 \\
20 & 0.001332 & 0.001408 & 0.001548 \\
\hline
\end{tabular}



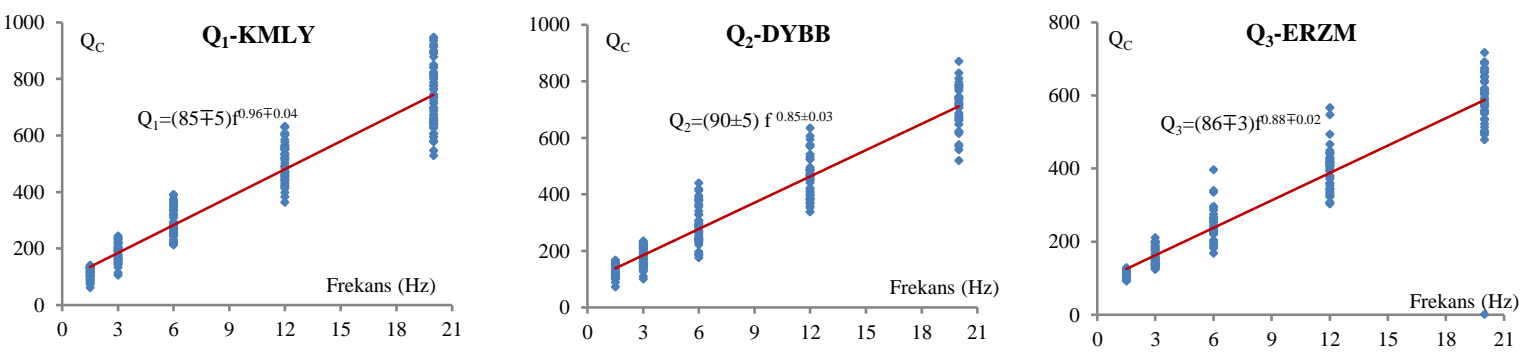

Şekil 4. Her ü̧̧ istasyon için $Q_{C}$ 'nin 1.5, 3, 6, $12,20 \mathrm{~Hz}$ frekanslarına ait grafiği ve fonksiyonu $Q_{C}(f)$. Mavi noktalar tek bir istasyon için 1.5, 3, 6, 12, $20 \mathrm{~Hz}$ frekanslarına ait $Q_{C}$ değerlerini temsil etmektedir.

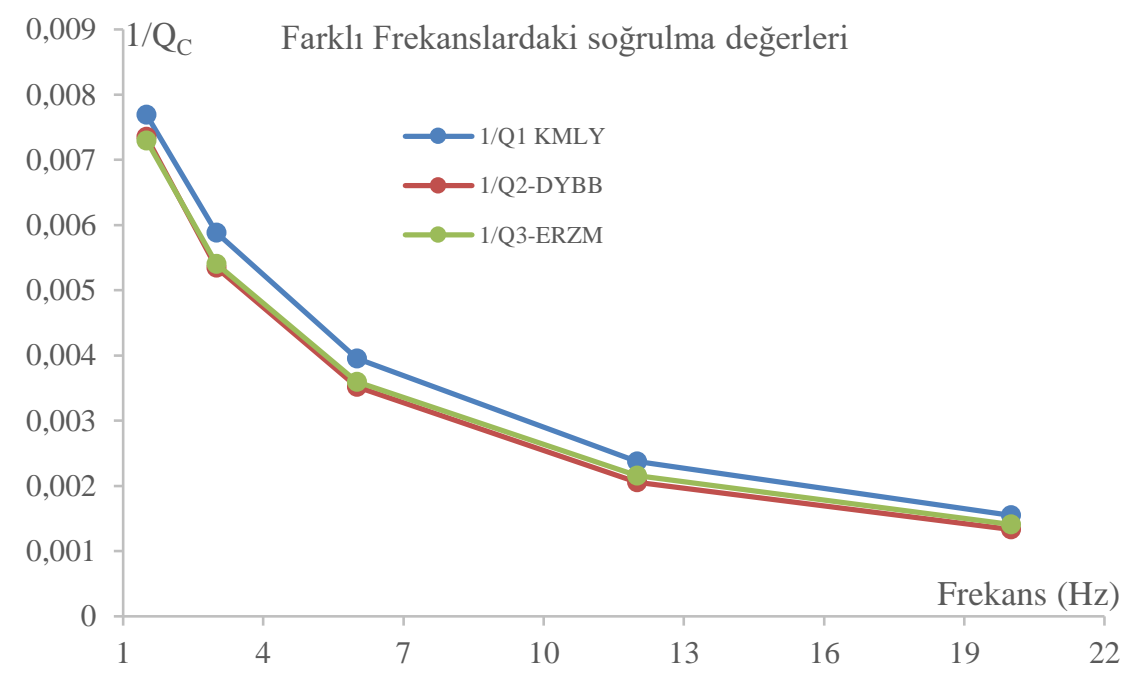

Şekil 5. Kemaliye, Diyarbakır ve Erzurum istasyonları için 1.5, 3, 6, 12, $20 \mathrm{~Hz}$ frekanslarına ait 1/QC (f) fonksiyonu.

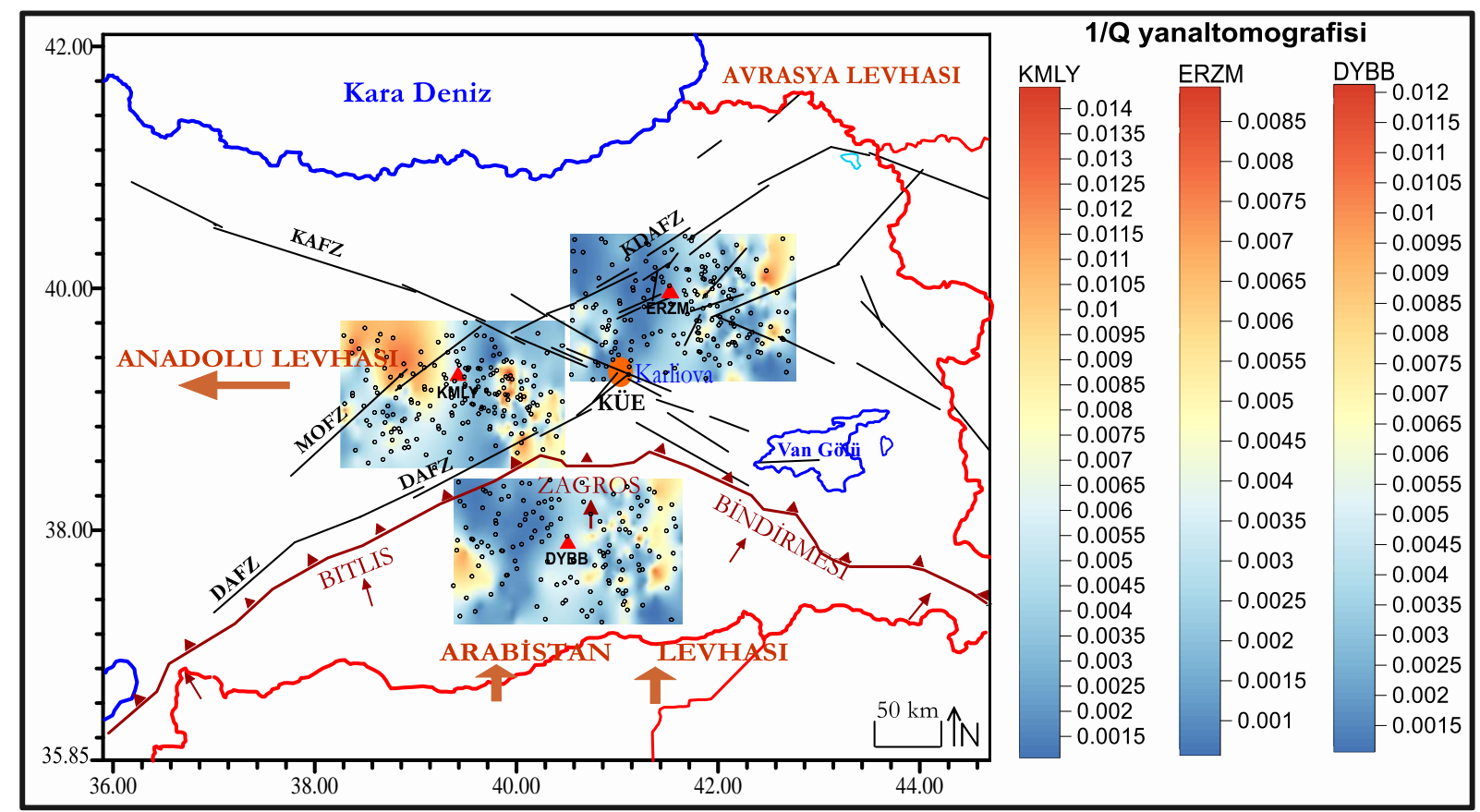

\section{Tartışma}

Q0'nun düşük değerinin ve yüksek frekans parametresinin kırılgan sünek bölgelerdeki tektonik stres yükünün etkisi olan litosferin üst kesimindeki sismik aktivite ve heterojenlikden kaynaklandığı ileri sürülmüştür (Aki, 2004). Sismik azalım, kabuğun tektonik 
rejimini tanımlamada gözlemlenebilir bir anahtar olarak kabul edilir (Romanowicz \& Mitchell, 2012). Bölgesel koda kalite faktörünün mekânsal değişimi, tektonik, sismisite, sismik risk analizi ve mühendislik sismolojisini daha iyi anlamak için kullanılmıştır (Jin \& Aki, 1988; Singh \& Herrmann, 1983).

Aktif tektonik bölgeler düşük Q0 değerleri ile ilişkilidir (Jin \& Aki, 1988; Mak, Chan, Chandler, \& Koo, 2004; Singh \& Herrmann, 1983). En yüksek frekans bağımlılığı ve en düşük Koda(Q0) değerlerinin KMLY istasyonundan elde edilmiş olması bu alanının DAFZ, MOFZ ve KAFZ' nun gibi büyük fay zonlarının etkisi altında olması ile açıklanabilir. En düşük frekans bağımlılığı ve en yüksek $\mathrm{Koda}(\mathrm{Q} 0)$ değerlerinin DYBB istasyonundan elde edilmiş olması bölgenin düşük sismik aktivitesi ile açıklanabilir. ERZM istasyonunun bu iki istasyon verişlerinin arasında bir değere sahip olması bu alanın diğer iki alana nazaran ara bir sismotektonik yapı ve ayrıca yükselme zonu olması ile açıklanabilir. Doğu Anadolu' da ERZ ve OLTU istasyonlarına ait 95 deprem verisi kullanarak episantr uzaklığı ve genlik ilişkisini kullanarak düşey S dalgasına ait kalite faktörü ve soğrulma katsayılarını hesaplamışlardır (Aydin \& Şahin, 2011). Doğu Anadolu'da dört istasyonda toplam 479 düşey S dalgası kayıtları kullanılarak $1 \mathrm{~Hz}$ frekansı için QC $=(97 \pm 4) \mathrm{f0.93} \pm 0.04$ olarak elde edilmiştir (Aydın, 2015). Bu değer çalışmadan elde edilen QC değerleri ile yakın bir değerdir. Bu çalışmadan elde ettiğimiz bulgular doğu Anadolu' da Sertçelik (2012) tarafından yapılan çalışmada elde edilen Qc=57.5f0.82 değerinden büyüktür. (Eyidoğan, Akıncı, Gündoğdu, Polat, \& Kaypak, 1996) tarafından 1992 Erzincan depremine ait arţ̧ı şoklardan 1.5 ile 24 Hz frekanslarımda 30 s kesme zamanı için elde edilen QS= 35f0.83 bizim bu değerlerden daha küçüktür. Bu farklılıkların aynı olmayan çalışma alanları, farklı metot ve farklı deprem kayıtları ve farklı cihazın etkilerinden kaynaklandığı söylenebilir. Çalışmanın genel sonucu yoğun tektonik yapılara sahip sismik olarak aktif bölgelerin, sabit alanlara kıyasla yüksek Q-1,düşük QC (yüksek zayıflatma), yüksek frekans bağımlılığı ile karakterize edildiğini göstermektedir. Her.

\section{Sonuçlar}

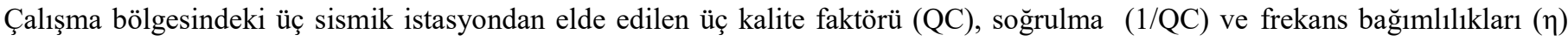
arasındaki değişimler belirlenerek yanal heterejonitesi ile tektonik ve sismisitesi arasındaki ilişki incelenmiştir. Çalışmanın en çarpıcı bulgusu Kemaliye'ye ait yanal soğrulma değerlerinin Erzurum ve Diyarbakır bölgelerinden oldukça farklı bulunması olmuştur. Buna bağlı olarak KAFZ ile MOFZ arasındaki alandan elde edilen soğrulma (1/QC) değerlerinde diğer iki istasyona nazaran belirgin bir artış gözlenmiştir. Bu durum KMLY istasyonunun diğer iki istasyona göre daha çok ve büyük fay zonları etkisi altında olmasından kaynaklanmış olabilir. KMLY istasyonunun çalışılan diğer iki istasyona nazaran en aktif depremselliğe ve tektonik aktiviteye sahip

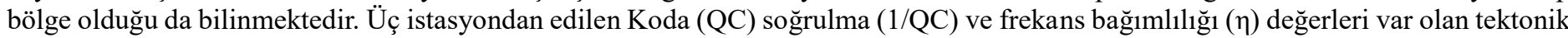
yapıları doğrular niteliktedir. Elde edilen kalite faktörü, frekans bağımlılığı ve soğrulma değerleri Arap plakasının Bitlis Zagros bindirmesini itmesi sonucunda oluşmuş üst kabuğa ait karmaşayı açıklar niteliktedir. Düşük Qc ve yüksek frekans bağımlılık değerleri Kemaliye'de elde edilmiş ve bu da tüm bölgelerde en yüksek tektonik aktiviteye sahip olduğunu göstermektedir. Çalışmadan elde edilen bulgular üç bölgeye ait sismisite ve tektonik yapı ile uyumludur. Doğu ve güneydoğu Anadolu'da seçilen üç bölgeye ait koda kalite faktörü (QC) ve soğrulma (1/QC) değerleri ile frekans bağımlılıkları ( $)$ verilerinin yanal değişimleri kabuğa ait tektonik yapıları ve sismik etkinlikleri ile uyum içindedir.

\section{Kaynakça}

Aki, K. (1969). Analysis of the seismic coda of local earthquakes as scattered waves. Journal of geophysical research, 74(2), 615-631.

Aki, K. (1980). Scattering and attenuation of shear waves in the lithosphere. Journal of Geophysical Research: Solid Earth, 85(B11), 6496-6504.

Aki, K. (2004). A new view of earthquake and volcano precursors. Earth, planets and space, 56(8), 689-713.

Aki, K., \& Chouet, B. (1975). Origin of coda waves: source, attenuation, and scattering effects. Journal of geophysical research, 80(23), 3322-3342.

Allen, C. R. (1969). Active faulting in northern Turkey.

Aydın, U. (2015). Estimation of seismodynamics differences and lateral variations of coda Q in Eastern Anatolia. Arabian Journal of Geosciences, 8(8), 6363-6370.

Aydin, U., \& Şahin, Ş. (2011). Comparison of the attenuation properties for two different areas in eastern Anatolia, Turkey. Soil Dynamics and Earthquake Engineering, 31(8), 1192-1195.

Barka, A., \& Kadinsky-Cade, K. (1988). Strike-slip fault geometry in Turkey and its influence on earthquake activity. Tectonics, 7(3), 663-684.

Bozkurt, E. (2001). Neotectonics of Turkey-a synthesis. Geodinamica acta, 14(1-3), 3-30.

Eyidoğan, H., Akıncı, A., Gündoğdu, O., Polat, O., \& Kaypak, B. (1996). Investigation of the recebt seismic activity of Gökova Basin. Paper presented at the National Marine Geology and Geophysical Programme Workshop I, Proceedings.

Giampiccolo, E., Gresta, S., \& Rascona, F. (2004). Intrinsic and scattering attenuation from observed seismic codas in southeastern Sicily (Italy). Physics of the Earth and Planetary Interiors, 145(1-4), 55-66.

Jin, A., \& Aki, K. (1988). Spatial and temporal correlation between coda Q and seismicity in China. Bulletin of the Seismological Society of America, 78(2), 741-769.

Johnston, D., \& Toksöz, M. (1981). Definitions and terminology: Seismic Wave Attenuation, Geophysics reprint series no. 2. Society of Exploration Geophysicists, Tulsa.

Ketin, I. (1969). Kuzey Anadolu fayi hakkinda. MTA Dergisi, 72, 1-27.

Knopoff, L. (1964). Q Rev. Geophysics, 2, 625-660.

Mak, S., Chan, L., Chandler, A., \& Koo, R. (2004). Coda Q estimates in the Hong Kong region. Journal of Asian Earth Sciences, 24(1), 127-136. 
McClusky, S., Reilinger, R., Mahmoud, S., Ben Sari, D., \& Tealeb, A. (2003). GPS constraints on Africa (Nubia) and Arabia plate motions. Geophysical Journal International, 155(1), 126-138.

McKenzie, D. (1970). Plate tectonics of the Mediterranean region. Nature, 226(5242), 239-243.

Rautian, T., \& Khalturin, V. (1978). The use of the coda for determination of the earthquake source spectrum. Bulletin of the Seismological Society of America, 68(4), 923-948.

Romanowicz, B., \& Mitchell, B. J. (2012). Q of the earth: Global, regional, and laboratory studies: Birkhäuser.

Sato, H. (1977). Energy propagation including scattering effects sengle isotropic scattering approximation. Journal of Physics of the Earth, 25(1), 27-41.

Sato, H., Fehler, M. C., \& Maeda, T. (2012). Seismic wave propagation and scattering in the heterogeneous earth (Vol. 496): Springer.

Sengor, A. (1980). Turkiye'nin neotektoniginin esasları (The principles of neotectonics of Turkey, in Turkish). Turkish Assoc Geol Press, Ankara, 2.

Sengör, A. (1979). The North Anatolian transform fault: its age, offset and tectonic significance. Journal of the Geological Society, 136(3), 269-282.

Singh, S., \& Herrmann, R. B. (1983). Regionalization of crustal coda Q in the continental United States. Journal of Geophysical Research: Solid Earth, 88(B1), 527-538.

Toksöz, M., Shakal, A., \& Michael, A. (1979). Space-time migration of earthquakes along the North Anatolian fault zone and seismic gaps. pure and applied geophysics, 117(6), 1258-1270. 